\title{
Resposta de híbridos de milho cultivados em diferentes épocas à população de plantas e ao despendoamento
}

\author{
Response of maize hybrids grown at different eras to plant population and tassel removal
}

\author{
Luís Sangoi $^{1}$ Altamir Frederico Guidolin ${ }^{2}$ Jefferson Luís Meirelles Coimbra ${ }^{3}$ \\ Paulo Regis Fereira da Silva ${ }^{4}$
}

\section{RESUMO}

Os híbridos contemporâneos de milho são mais tolerantes à elevação da população de plantas do que os híbridos antigos. É possível que a melhor adaptação da cultura ao adensamento esteja relacionada com a menor dominância apical do pendão sobre a espiga. Este trabalho foi conduzido objetivando avaliar a evolução na tolerância de híbridos de milho liberados comercialmente em diferentes épocas à elevação na população de plantas, bem como observar se o progresso obtido esta associado à redução na dominância apical. O experimento foi conduzido no município de Lages, SC, durante os anos agrícolas de 1999/2000 e 2000/2001. Utilizou-se o delineamento experimental de parcelas subsubdivididas. $\mathrm{Na}$ parcela principal, foram testadas três populações de planta: 50.000, 75.000 e 100.000pl ha' ${ }^{-1}$ Nas subparcelas, foram alocados quatro híbridos: $\mathrm{Ag} 12, \mathrm{Ag} 28$, Ag 303 e Ag 9012, liberados comercialmente para cultivo nas décadas de 60, 70, 80 e 90, respectivamente. Cada híbrido de milho foi analisado com pendões intactos e integralmente removidos durante o emborrachamento nas sub-subparcelas. Os ensaios foram implantados em 30/10/1999 e 2/11/2000. A por meio de análise de variância e de regressão polinomial. $O$ híbrido Ag 9012, liberado comercialmente para cultivo na década de 90, foi mais exigente em população de plantas do que os híbridos antigos para otimizar o seu potencial produtivo em 1999/2000, quando as condições foram favoráveis à obtenção de rendimentos de grão superiores a $10.000 \mathrm{~kg} \mathrm{ha}^{-1}$. Neste ano agrícola, a interferência do pendão sobre o desenvolvimento das espigas foi pequena. Por outro lado, o rendimento de grãos de todos os híbridos respondeu positivamente ao despendoamento em 2000/2001, sob tetos produtivos mais baixos. Não houve associação entre maior tolerância ao adensamento e resposta ao despendoamento, indicando que a tolerância a altas densidades populacionais não esteve relacionada com a redução da dominância apical do pendão sobre as espigas.
Palavras-chave:: Zea mays, cultivar, densidade de semeadura, pendão.

\begin{abstract}
Current maize hybrids are more tolerant to the increasing of plant population than the hybrids used in the past. It is possible that modern hybrid's better adaptation to crowding is related to the lower apical dominance of the tassel over the ear. This experiment was aimed at evaluating the evolution on maize hybrids commercially released in different times the increase in plant population and at detecting if this progress is related to the reduction of apical dominance. The experiment was carried out in Lages, SC, during the 1999/ 2000 and 2000/2001 growing seasons. A split-split plot design was used. Three plant populations were tested in the main plots: 50,000, 75,000 and 100,000pl ha-1. Four hybrids commercially released in the 60's, 70's, 80's and 90's, respectively, were assessed in the split plots. Each hybrid was analyzed with preserved tassels and with tassel removed at booting in the split-split plot. The trials were installed in 10/30/ 1999 and 11/02/2000. Grain yield was assessed using the variance and regression analyzes. The hybrid commercially released in the 90's (Ag 9012) was more demanding in plant population to maximize grain yield when the conditions were favorable to yields higher than $10,000 \mathrm{~kg} \mathrm{ha}^{-1}$ (1999/2000). At this scenario, tassel interference on ear development was small. On the other hand, grain yield of all tested hybrids was increased by tassel removal under a lower yield plateau (2000/ 2001).There was no association between higher tolerance to crowding and greater response to detasseling, indicating that the tested hybrid higher endurance to dense stands was not related to the reduction in apical dominance of the tassel over the ear.
\end{abstract}

Key words: Zea mays, cultivar, sowing density, tassel.

${ }^{1}$ Universidade do Estado de Santa Catarina (UDESC), CP 281, 88520-000, Lages, Santa Catarina, Brasil. E-mail:a2ls@cav.udesc.br. Autor para correspondência.

${ }^{2}$ UDESC, Lages, SC, Brasil.

${ }^{3}$ Programa de Pós-graduação em Fitomelhoramento, Universidade Federal de Pelotas (UFPel), Pelotas, RS, Brasil.

${ }^{4}$ Universidade Federal do Rio Grande do Sul (UFRGS), Porto Alegre, RS, Brasil. 


\section{INTRODUÇÃO}

Entre as gramíneas de importância econômica, o milho é a única que apresenta uma organização floral monóica. O desenvolvimento vegetativo do pendão precede ao da espiga porque a inflorescência masculina é diferenciada ontogeneticamente antes da feminina (CHENG \& PAREDY, 1994).

Estruturas apicais normalmente têm prioridade na utilização dos recursos disponíveis para o crescimento dos vegetais, especialmente de água, nutrientes e fotoassimilados. Por este motivo, o pendão, que possui uma posição apical, tende a controlar o desenvolvimento de outros órgãos da planta de milho (PATERNIANI, 1981).

As diferenças observadas em termos de localização e época de diferenciação e desenvolvimento do pendão e da espiga podem promover uma competição entre as duas inflorescências, especialmente quando a planta é submetida a estresses bióticos e abióticos. Nestes casos, o pendão pode suprimir o desenvolvimento adequado da espiga por meio de três diferentes mecanismos: sombreando as folhas superiores da planta, competindo diretamente por fotoassimilados e produzindo e exportando reguladores de crescimento em quantidades superiores às necessárias para o desenvolvimento da inflorescência feminina (SANGOI, 1996).

A competição entre inflorescências determina um comportamento protândrico da planta, o qual favorece o desenvolvimento da estrutura masculina em detrimento da feminina (SANGOI, 2001). A intensidade da competição entre o pendão e a espiga está relacionada com as condições de ambiente e com o tipo de manejo empregado na cultura. Restrições na disponibilidade hídrica e incrementos excessivos na população de plantas são fatores que estimulam a dominância apical do pendão sobre as espigas (SANGOI \& SALVADOR, 1998). Nestes casos, o retardamento no desenvolvimento da inflorescência feminina estimula a assicronia entre a antese e o espigamento, reduzindo o número de grãos produzidos por espiga (BOLAGNOS \& EDMEADES, 1996).

Trabalhos conduzidos por DUVICK \& CASSMANN (1999), TOLLENAAR \& LEE (2002), SANGOI et al. (2002) e TOKATLIDES \& KOUTROUBAS (2004) demonstraram que os híbridos contemporâneos de milho são mais tolerantes ao estresse provocado pela alta densidade de plantas do que os híbridos antigos. DUVICK \& CASSMANN (1999) constataram que uma das mudanças introduzidas pelos programas de melhoramento nos híbridos cultivados mais recentemente no cinturão do milho americano foi a redução no tamanho do pendão. Pendões menores exercem menor dominância apical sobre as espigas, característica importante sob condições de estresse. Assim, é possível que o menor investimento da planta no desenvolvimento da inflorescência masculina contribua para a melhor adaptação da cultura ao adensamento.

Uma forma prática de se avaliar indiretamente os efeitos negativos do pendão sobre as espigas é removendo mecanicamente a inflorescência masculina antes de sua extrusão da folha bandeira. Teoricamente, quanto mais acentuada a dominância apical, maiores serão os benefícios do despendoamento sobre o rendimento de grãos (SANGOI, 1996).

Experimentos avaliando a evolução na tolerância ao adensamento de híbridos de milho desenvolvidos em diferentes épocas para a Região Sul do Brasil são escassos. Da mesma forma, não há dados disponíveis sobre os níveis de dominância apical de híbridos liberados comercialmente para cultivo no país durante a segunda metade do século XX.

Com base no exposto acima, o presente trabalho teve como objetivo avaliar a resposta de híbridos de milho liberados para cultivo em diferentes épocas ao aumento da população de plantas e ao despendoamento, procurando quantificar a evolução na tolerância da cultura ao adensamento e observar se este progresso esteve associado à redução na dominância apical.

\section{MATERIAL E MÉTODOS}

O experimento foi conduzido a campo, nos anos agrícolas de 1999/2000 e 2000/2001, no município de Lages, SC, cujas coordenadas geográficas são 2752’30” de latitude sul e 50¹8’30” de longitude oeste. O solo da área experimental é um Nitossolo Vermelho (EMBRAPA, 1999), o qual apresentava as seguintes características químicas no início da implantação do trabalho: $\mathrm{pH}$ em $\mathrm{H}_{2}$ 0 - 6,6; $\mathrm{pH} \mathrm{SMP} \mathrm{-} \mathrm{6,3;} \mathrm{P}-3,8 \mathrm{mg} \mathrm{kg}^{-1}$; $\mathrm{K}-187 \mathrm{mg} \mathrm{kg}^{-1}$; M.O. - $40 \mathrm{~g} \mathrm{~kg}^{-1} ; \mathrm{Al}-0 \mathrm{me} \mathrm{dl}^{-1} ; \mathrm{Ca}+\mathrm{Mg}$ $-9,4 \mathrm{me} \mathrm{dl}^{-1}$.

O delineamento experimental utilizado foi o de blocos ao acaso, em parcelas sub-subdivididas. A combinação de três fatores foi estudada em cada ano agrícola: população de plantas, híbridos e níveis de despendoamento. Na parcela principal, foram testadas três populações de planta: 50.000, 75.000 e 100.000pl ha $^{-1}$. Nas subparcelas foram alocados quatro híbridos: Ag 12, Ag 28, Ag 303 e Ag 9012, liberados comercialmente para cultivo nas décadas de 60, 70, 80 
e 90, respectivamente. Cada híbrido de milho foi analisado com pendões intactos e integralmente removidos durante o emborrachamento nas subsubparcelas. Nos tratamentos envolvendo despendoamento, a inflorescência masculina foi removida manualmente em todas as plantas das duas fileiras centrais de cada parcela, antes da extrusão da folha bandeira, entre os estádios V18 e V20 da escala proposta por RITCHIE et al. (1993).

As sub-subparcelas foram constituídas por quatro linhas de seis metros de comprimento, espaçadas entre si em $80 \mathrm{~cm}$. Os espaçamentos entre plantas na linha foram de 25, 16,6 e $12,5 \mathrm{~cm}$, para as densidades de 50.000, 75.000 e 100.000pl ha-1, respectivamente. Foram utilizadas quatro repetições por tratamento.

O solo foi preparado no sistema convencional, com uma aração e duas gradagens. A semeadura foi realizada com plantadeiras manuais, em $30 / 10 / 1999$ e $2 / 11 / 2000$. Foram aplicados $30 \mathrm{~kg}$ de N, $120 \mathrm{~kg}$ de $\mathrm{P}_{2} \mathrm{O}_{5}$ e $90 \mathrm{~kg}$ de $\mathrm{K}_{2} \mathrm{O}$ na semeadura. Logo após a semeadura, uma mistura de atrasine (925g i.a. ha ${ }^{-1}$ ) e metolachlor (725g i.a. ha ${ }^{-1}$ ) foi aspergida sobre a superfície do solo para o controle de plantas daninhas. A adubação de cobertura foi realizada quando as plantas estavam com seis a sete folhas totalmente expandidas, de acordo com a escala de RITCHIE et al. (1993), aplicando-se $110 \mathrm{~kg}$ de $\mathrm{N} \mathrm{ha}^{-1}$ na forma de uréia. Quando a cultura se encontrava com quatro e oito folhas expandidas, efetuou-se duas aplicações do inseticida lufenuron (15g i.a. ha-1) para o controle de Spodoptera frugiperda.

A colheita foi realizada em 5/05/2000 e 7/04/ 2001, quando todas as folhas da planta se encontravam senescidas. O rendimento de grãos foi computado nas duas fileiras centrais de cada sub-subparcela, excetuando-se meio metro nas extremidades de cada linha. Os dados obtidos foram avaliados estatisticamente por meio de análise de variância, utilizando-se o teste F, ao nível de significância de 5\%, por meio do pacote SAS, versão Learning Edition, conforme descrito por COIMBRA et al. (2004). Quando alcançada significância estatística, as diferenças entre médias foram estimadas por meio de análise de regressão polinomial para o fator quantitativo (população de plantas) e pelo teste de Tukey para os fatores qualitativos (híbrido e despendoamento), ao nível de probabilidade de erro de 5\%.

\section{RESULTADOS E DISCUSSÃO}

Os dois anos agrícolas avaliados apresentaram chuvas bem distribuídas ao longo de todo o ciclo da cultura, não havendo períodos prolongados de estiagem, principalmente durante os meses de janeiro e fevereiro, nos quais se concentraram as fases de florescimento e enchimento de grãos da cultura. O clima favorável e o bom nível de fertilidade da área experimental contribuíram para a obtenção de rendimentos de grãos elevados, principalmente no primeiro ano agrícola, quando a produtividade superou a $10.000 \mathrm{~kg} \mathrm{ha}^{-1}$, mesmo nos genótipos liberados comercialmente para cultivo nas décadas de 60 e 70 (Figura 1). Os tetos produtivos foram menores na segunda estação de crescimento, possivelmente em função do cultivo sucessivo de milho por dois anos consecutivos na mesma área.

Em 1999/2000, o rendimento de grãos foi significativamente influenciado pelo efeito simples de híbrido e pelas interações entre híbrido e densidade e entre híbrido e despendoamento (Tabela 1). Já no ano agrícola de 2000/2001, as variações significativas do rendimento de grãos deveram-se aos efeitos principais dos fatores híbrido e despendoamento.

O efeito da interação entre densidade de semeadura e híbrido sobre o rendimento de grãos em 1999/2000 demandou a descrição qualitativa da interação simples. Neste sentido, a análise de variação atribuível ao fator densidade de semeadura foi apresentada separadamente para cada híbrido comercial testado na tabela 2.

No presente estudo, havia particular interesse em analisar a curva de resposta do rendimento de grãos dos híbridos testados à elevação da população de plantas. A significância da interação densidade x híbridos ressaltou a necessidade de ajustar curvas distintas para os diferentes níveis do fator quantitativo. Em função disto, a análise de variância prosseguiu para o estudo da variação atribuível ao fator quantitativo, separadamente para cada nível do fator qualitativo, por meio da decomposição dos graus de liberdade.

Esta análise indicou que a variação significativa atribuível à densidade de plantas na lavoura foi eminentemente quadrática para todos os híbridos testados (Tabela 2). A utilização de populações de planta superiores a $50.000 \mathrm{pl} \mathrm{ha}^{-1}$ promoveu decréscimo no rendimento de grãos do híbrido Ag 12 (Figura 1). Por outro lado, houve incremento no rendimento de grãos dos outros três híbridos com a utilização de densidades superiores a 50.000pl ha-1. As populações teóricas que maximizaram o rendimento de grãos foram de 68.750, 80.218 e 82.029pl ha-1 para os híbridos Ag 28, Ag 303 e Ag 9012, respectivamente. Deve-se destacar que os coeficientes de determinação foram baixos no presente estudo. Possivelmente a utilização de um maior número de densidades de planta 


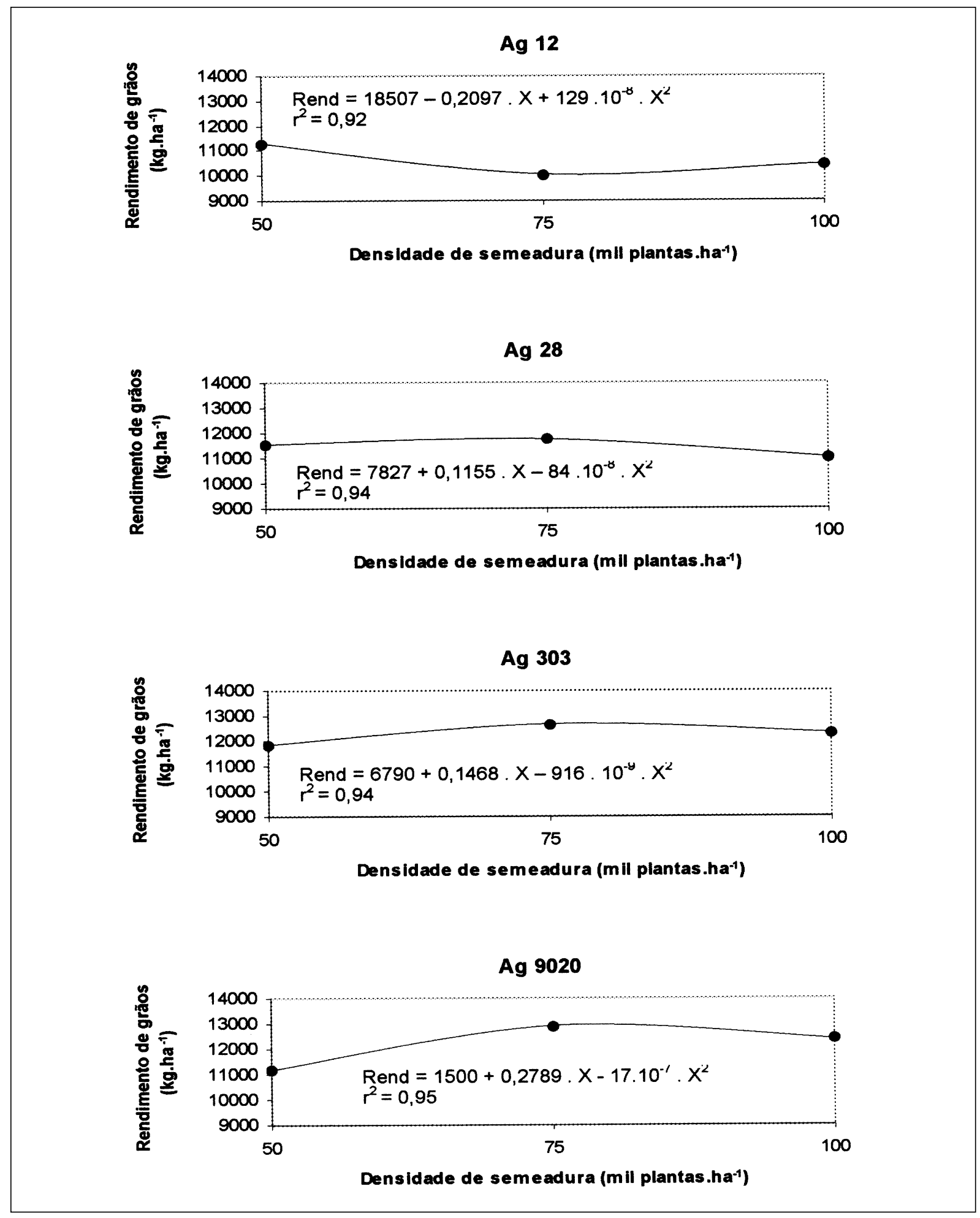

Figura 1 - Rendimento de grãos de híbridos de milho das décadas de 60 (Ag 12), 70 (Ag 28), 80 (Ag 303) e 90 (Ag 9012) em diferentes densidades de semeadura. Lages, SC, 1999/2000.

Ciência Rural, v.36, n.5, set-out, 2006. 
permitiria uma melhor caracterização da resposta quadrática dos híbridos ao incremento na população.

Os dados obtidos no primeiro ano agrícola confirmaram as ponderações feitas por DUVICK \& CASSMANN (1999), TOLLENAAR \& WU (1999), SANGOI (2001) e TOLLENAAR \& LEE (2002) de que os híbridos contemporâneos de milho são mais exigentes em população de planta do que os híbridos antigos, a fim de otimizarem o seu potencial produtivo sob condições edafo-climáticas que favoreçam a obtenção de altos tetos de rendimento. Já no segundo ano agrícola, em que os valores de rendimento de grãos foram menores, não se observou efeito significativo da densidade de plantas, nem tão pouco uma resposta diferenciada do rendimento de grãos dos híbridos ao incremento da população (Tabela 1).

A remoção do pendão afetou o rendimento de grãos dos híbridos testados nos dois anos agrícolas em que se conduziu o trabalho, isoladamente em 2000/ 2001 e na interação com os híbridos em 1999/2000 (Tabela 1). A magnitude deste impacto dependeu da estação de crescimento. Em 1999/2000, apenas o rendimento de grãos do híbrido Ag 303 foi incrementado pela retirada da inflorescência masculina (Tabela 3). Neste ano agrícola, os híbridos liberados comercialmente para cultivo mais recentemente (Ag 303 e Ag 9012) foram mais produtivos do que os híbridos mais antigos (Ag 12 e Ag 28), tanto nas parcelas com pendão intacto quanto naquelas em que ele foi removido.
Na segunda estação de crescimento, a remoção do pendão aumentou significativamente o rendimento de grãos, independentemente da época de liberação do híbrido comercial (Tabela 3). Considerando-se a média dos genótipos testados, o rendimento de grãos das parcelas despendoadas superou em $605 \mathrm{~kg} \mathrm{ha}^{-1} \mathrm{o}$ das parcelas nas quais a inflorescência masculina foi preservada, o que representou um acréscimo de $7 \%$ na produtividade média dos genótipos utilizados no ensaio. Em 2000/ 2001, o híbrido Ag 9012 foi mais produtivo do que as demais cultivares, independentemente do destino da inflorescência masculina.

Os dados obtidos neste trabalho demonstram que a influência do pendão sobre a performance agronômica da cultura do milho depende dos tetos de rendimento obtidos. Sob condições edafoclimáticas e de manejo que favoreçam a obtenção de produtividades elevadas, tais como as verificadas em 1999/2000, a interferência da inflorescência masculina sobre o desenvolvimento da espiga foi menor e os benefícios do despendoamento menos pronunciados. Por outro lado, com tetos produtivos mais baixos, tais como os obtidos em 2000/2001, a natureza protândrica da planta se manifestou mais claramente, acentuando as vantagens da remoção do pendão(SANGOI \& SALVADOR, 1998; SANGOI et al., 2003).

Uma das hipóteses deste trabalho era a de que os híbridos antigos apresentam dominância apical

Tabela 1 - Resumo da análise de variância, indicando graus de liberdade (GL) e os quadrados médios para o rendimento de grãos de quatro híbridos de milho, liberados comercialmente para cultivo nas décadas de 60, 70, 80 e 90, submetidos a três densidades de plantas (50.000, 75.000 e 100.000 plantas. ha ${ }^{-1}$ ), em dois anos agrícolas (1999/2000 e 2000/2001), com os pendões intactos ou removidos. Lages, SC.

\begin{tabular}{lllc}
\hline & & & Quadrados Médios \\
Fonte de variação & Graus de liberdade & Ano 1999/2000 & Ano 2000/2001 \\
\cline { 3 - 4 } & & $2.148 .554,72$ & $1.699 .288,11$ \\
Bloco (B) & 3 & $1.244 .735,07$ & 1055548,45 \\
Densidade (D) & 2 & $306.741,75$ & $903.641,06$ \\
D*B - Erro A & 6 & $14.862 .060,47^{*}$ & $4.702 .348,06^{*}$ \\
Hibrido (H) & 3 & $3.454 .017,42^{*}$ & $552.480,34$ \\
D*H & 6 & $905.873,45$ & $898.936,74$ \\
B*B(D) - Erro B & 27 & $240.600,38$ & $8.774 .922,67^{*}$ \\
Despendoamento (De) & 1 & $631.571,09$ & $144.192,95$ \\
De*D & 2 & $1.965 .473,74^{*}$ & $692.425,00$ \\
De*H & 3 & $957.929,75$ & $547.857,20$ \\
De* D*H & 6 & $425.932,77$ & $596.836,59$ \\
De*B(D*H) - Erro C & 36 & 11.609 & 8.952 \\
Média geral & & & \\
\hline
\end{tabular}

${ }^{*}$ Efeitos significativos pelo teste $\mathrm{F}(\mathrm{P}<0,05)$. 
Tabela 2 - Resultados da análise de variação para o rendimento de grãos com a decomposição da variação atribuível à densidade de plantas para cada híbrido de milho estudado $\left(\mathrm{H}_{1}=\mathrm{Ag} 12 ; \mathrm{H}_{2}=\mathrm{Ag} 28 ; \mathrm{H}_{3}=\mathrm{Ag} 303 ; \mathrm{H}_{4}=\right.$ Ag 9012), nos componentes polinomial linear e quadrático, no ano agrícola de 1999/2000. Lages, SC.

\begin{tabular}{lcl}
\hline Fonte de variação & $\begin{array}{c}\text { Graus de } \\
\text { liberdade }\end{array}$ & $\begin{array}{c}\text { Quadrados } \\
\text { médios }\end{array}$ \\
\hline Densidade $\mid \mathrm{H}_{1}$ & 2 & $3.025 .347^{*}$ \\
Densidade $\mid \mathrm{H}_{2}$ & 2 & 1.287 .826 \\
Densidade $\mid \mathrm{H}_{3}$ & 2 & 1.319 .630 \\
Densidade $\mid \mathrm{H}_{4}$ & 2 & $601.3985^{*}$ \\
Densidade $\mid \mathrm{H}_{1}$ linear & & \\
Densidade $\mid \mathrm{H}_{1}$ quadrático & 1 & $2.576 .827,56^{*}$ \\
Densidade $\mid \mathrm{H}_{2}$ linear & 1 & $3.473 .866,02^{*}$ \\
Densidade $\mid \mathrm{H}_{2}$ quadrático & 1 & $1.105 .652,25$ \\
Densidade $\mid \mathrm{H}_{3}$ linear & 1 & $3.470 .000,00^{*}$ \\
Densidade $\mid \mathrm{H}_{3}$ quadrático & 1 & $891.608,06$ \\
Densidade $\mid \mathrm{H}_{4}$ linear & 1 & $4.747 .651,699^{*}$ \\
Densidade $\mid \mathrm{H}_{4}$ quadrático & 1 & $1.290 .496,00$ \\
Erro-B* $\mathrm{H}\left(\mathrm{A}^{*} \mathrm{D}\right)$ & 27 & $905.873,35$ \\
\hline
\end{tabular}

${ }^{*}$ Efeitos significativos pelo teste $\mathrm{F}(\mathrm{P}<0,05)$.

do pendão sobre a espiga mais acentuada do que os híbridos liberados para cultivo mais recentemente, característica que aumentaria a resposta do rendimento de grãos ao despendoamento e dificultaria a performance agronômica destes materiais sob altas densidades populacionais. Os resultados obtidos nos dois anos em que se conduziu o trabalho não confirmaram esta hipótese. Houve efeito diferenciado da elevação da população de plantas sobre o rendimento de grãos dos genótipos em 1999/2000 (Tabelas 1 e 2), com melhor reposta do rendimento de grãos ao adensamento do híbrido mais recente (Figura 1). Contudo, tanto o Ag 9012 quanto os híbridos liberados para cultivo nas décadas de 60 e 70 (Ag 12 e Ag 28) não responderam ao despendoamento naquele ano (Tabela 3). Já em 2000/2001, quando não houve efeito significativo da densidade de plantas sobre o rendimento de grãos, a remoção do pendão elevou a produtividade de todos os híbridos. Assim, pode-se inferir que não houve uma relação direta entre maior tolerância ao adensamento e menor dominância apical nos genótipos utilizados neste trabalho.

\section{CONCLUSÕES}

O rendimento dos híbridos de milho liberados mais recentemente para cultivo sofreu maior incremento com a utilização de populações de plantas superiores a $50.000 \mathrm{pl} \mathrm{ha}^{-1}$ sob condições edafoclimáticas e de manejo favoráveis à obtenção de produtividades elevadas.

A dominância apical foi maior e os benefícios da prática do despendoamento sobre o rendimento mais consistentes quando os tetos produtivos da cultura foram menores.

Não houve uma relação direta entre menor dominância apical e maior tolerância de híbridos de milho ao adensamento.

Tabela 3 - Efeito do despendoamento sobre o rendimento de grãos de híbridos de milho liberados comercialmente para cultivo em diferentes épocas, na média de cinco populações de planta. Lages, SC.

\begin{tabular}{|c|c|c|c|c|c|}
\hline \multirow[t]{2}{*}{ Pendão } & \multicolumn{4}{|c|}{ Híbrido $^{1}$} & \multirow[t]{2}{*}{ Média } \\
\hline & $\underline{\operatorname{Ag} 12}$ & $\underline{\operatorname{Ag} 28}$ & Ag 303 & Ag 9012 & \\
\hline & & -----Ano agr & 99/2000----- & ------------ & \\
\hline Intacto & b $10.858^{*} \mathrm{~A}$ & b $11.203 \mathrm{~A}$ & a $11.914 \mathrm{~B}$ & a $12.261 \mathrm{~A}$ & 11.559 \\
\hline Removido & с 10.298 B & b $11.623 \mathrm{~A}$ & a $12.624 \mathrm{~A}$ & Ab $12.089 \mathrm{~A}$ & 11.658 \\
\hline \multirow[t]{2}{*}{ Média } & 10.578 & 11.413 & 12.269 & 12.175 & 11.608 \\
\hline & & -----Ano ag & 000/2001--- & ---------- & \\
\hline Intacto & 8.371 & 8.210 & 8.569 & 9.446 & $8.649 \mathrm{~B}$ \\
\hline Removido & 9.117 & 9.229 & 8.885 & 9.784 & $9.254 \mathrm{~A}$ \\
\hline Média & b 8.744 & b 8.720 & b 8.727 & a 9.615 & 8.951 \\
\hline
\end{tabular}

${ }^{1 /}$ Ag 12 - híbrido liberado comercialmente para cultivo na década de 60; Ag 28 - híbrido liberado comercialmente para cultivo na década de 70; Ag 303 - híbrido liberado comercialmente para cultivo na década de 80; Ag 9012 - híbrido liberado comercialmente para cultivo na década de 90 .

* Médias antecedidas por mesma letra minúscula na linha ou sucedidas por mesma letra maiúscula na coluna, dentro de cada ano agrícola, não diferem significativamente pelo teste de Tuckey $(\mathrm{P}<0,05)$. 


\section{REFERÊNCIAS}

BOLAÑOS, J.; EDMEADES, G. The importance of the anthesissilking interval in breeding for drought tolerance in tropical maize. Field crops research, Amsterdan, v.31, n.2, p.233252, 1996.

CHENG, P.C.; PAREDY, D.R. Morphology and development of the tassel and ear. In: FREELING, M.; WALBOT, V. The maize handbook. NewYork: Springler-Verlag, 1994. Cap.3, p.37-47.

COIMBRA, J.L.M. et al. Fundamentos do SAS aplicado à experimentação agrícola. Pelotas: UFPel, 2004. 246p.

DUVICK, D.N.; CASSMAN, K.G. Post-green revolution trends in yield potential of temperate maize in the North-Central United States. Crop Science, Madison, v.39, n.6, p.16221630, 1999.

EMBRAPA. Centro Nacional de Pesquisa de Solos. Sistema brasileiro de classificação de solos. Brasília: EMBRAPA, 1999. 412p.

PATERNIANI, E. Influence of tassel size on ear placement in maize. Maydica, Bergamo, v.26, n.1, p. 85-91, 1981.

RITCHIE, S.W. et al. How a corn plant develops. Ames: Iowa State University of Science and Technology, 1993. 26p. (Special Report, 48).

SANGOI, L. An ideotype of maize for conditions of high temperature and low moisture. 1996. 350f. Tese
(Doutorado em Crop Production and Plant Physiology) - Iowa State University of Science and Technology.

SANGOI, L. Understanding plant density effects on maize growth and development: an important issue to maximize grain yield. Ciência Rural, Santa Maria, v.31, p.159-168, 2001.

SANGOI, L.; SALVADOR, R.J. Effect of maize plant detasseling on grain yield tolerance at high plant density an drought stress. Pesquisa Agropecuária Brasileira, Brasília, v.33, n.5, p.677-684, 1998.

SANGOI, L. et al. Response of Brazilian maize hybrids from different eras to changes in plant density. Field Crops Research, Amsterdan, v.79, n.1, p.39-51, 2002.

SANGOI, L. et al. Bases morfo-fisiológicas para aumentar a tolerância de cultivares de milho a altas densidades de plantas. In: REUNIÃO TÉCNICA CATARINENSE DE MILHO E FEIJÃO, 4.,, 2003, Lages, SC. Resumos Expandidos... Lages: CAV-UDESC, 2003. V.4, 280p. p.19-24.

TOKATLIDIS, I.S; KOUTROUBAS, S.D. A review of maize hybrids' dependence on high plant populations and its implications for crop yield stability. Field Crops Research, Amsterdan, v.88, n.1, p.103-114, 2004.

TOLLENAAR, M; WU, J. Yield improvement in temperate maize is attributable to greater stress tolerance. Crop Sciense, Madison, v.39, p.1597-1604, 1999.

TOLLENAAR, M.; LEE, E. Yield potential, yield stability and stress tolerance in maize. Field Crops Research, Amsterdan, v.75, p.161-169, 2002 